\title{
Promovendo o conhecimento sobre mulheres na Computação: experiência com o jogo de cartas Computasseia no ensino de História da Computação
}

\author{
Ana Iza Alencar, Valéria Maria Pinheiro, Anna Beatriz Marques \\ Universidade Federal do Ceará (UFC) - Campus Russas \\ Russas - CE - Brasil \\ \{anaizaalencar, valeriam.soft\}@alu.ufc.br, beatriz.marques@ufc.br
}

Abstract. Women were very important for the History of Computing, however, throughout the process, women were excluded from historical reports. This paper describes a teaching-learning experience with a existing card game called Computasseia which addresses the History of Computing, showing its main events and important personalities, showing the image and importance of women who collaborated for the area. We adopted and evaluated the game with high school and undergraduate students. The results indicate that the experience contributed for the construction of students' knowledge, enhancing interest in the area of Computing and the interaction among the players.

Resumo. As mulheres foram de grande importância na História da Computação, porém ao longo do processo foram excluídas dos relatos históricos. Este artigo descreve a experiência de ensino-aprendizado com um jogo de cartas existente denominado Computasseia, que aborda a História da Computação, com seus principais acontecimentos e personalidades importantes, mostrando a imagem e a importância das mulheres que colaboraram para a área. O jogo foi adotado e avaliado com estudantes do ensino médio e graduação. Os resultados indicam que a experiência contribuiu para a construção do conhecimento dos estudantes, potencializando o interesse pela área de Computação e a interação entre os jogadores.

\section{Introdução}

De acordo com Pessoa et al. (2017), a participação da mulher no desenvolvimento e disseminação da ciência foi de grande importância, sendo possível destacar Ada Lovelace, com a criação do primeiro algoritmo, Grace Hopper, idealizadora do conceito de sub-rotinas e Dana Urely, primeira mulher engenheira a participar de um projeto na NASA. Mesmo com a grande participação feminina na ciência, o número de ingressantes nos cursos da área de tecnologia é baixo. Segundo Oliveira et al. (2014) a partir dos anos 80 houve um decréscimo no número de mulheres concluintes nos cursos de computação.

As mulheres e suas obras na ciências são pouco reconhecidas, frequentemente seus nomes são esquecidos da história e com a computação não é diferente (Oreskes, 1996). Como exemplo, as programadoras do ENIAC só foram reconhecidas 
historicamente depois de décadas de sua atuação ${ }^{1}$. Desta forma, ao ensinar História da Computação é indispensável que a participação feminina seja incluída, tanto pelo respeito à história, como também é um fator que pode atrair mulheres para a área da Computação (Figueiredo e Santos, 2016).

Esse artigo apresenta um conjunto de experiências de ensino-aprendizagem com um jogo de cartas existente chamado Computasseia, proposto por Figueiredo e Santos (2016). O jogo aborda a História da Computação, mostrando datas, personagens e fatos importantes da Computação, de maneira lúdica. Com o intuito de promover a estudantes do ensino médio e superior conhecimentos sobre a História da Computação, o jogo Computasseia foi adotado como metodologia de ensino-aprendizagem em três turmas distintas. Esta pesquisa contribui com evidências a respeito do uso do Computasseia, pois além dos trabalhos que relatam a proposta do jogo (Figueiredo e Santos, 2016; Santos e Figueiredo, 2016) não existiam relatos de experiência do seu uso em diferentes contextos educacionais.

O restante deste artigo está organizado da seguinte forma: a Seção 2 apresenta o objetivo, as cartas e as regras do Computasseia. A Seção 3 relata a metodologia utilizada durante a experiência de ensino-aprendizagem com o jogo Computasseia. $\mathrm{Na}$ Seção 4, os resultados obtidos por meio do questionário são apresentados. Por fim, a Seção 5 finaliza o artigo e apresenta vertentes para trabalhos futuros.

\section{O Jogo Computasseia}

O Computasseia ${ }^{2}$ é um jogo de cartas de estratégia desenvolvido, prioritariamente, para dar suporte ao ensino da História da Computação em diferentes níveis de ensino (técnico, graduação e pós-graduação) (Figueiredo e Santos, 2016). O objetivo do jogo é a construção da linha do tempo contendo os principais marcos históricos de eventos, instituições e personalidades da Computação, através da distribuição sequencial em ordem crescente da data das cartas. Cada carta possui elementos visuais que fomentam a curiosidade e o aprendizado, como: título, imagem ilustrativa, área de conhecimento, categoria, descrição e data, apresentados na Figura 1.

A dinâmica do jogo deve ser realizada com grupos de dois a seis jogadores. No início do jogo, cada jogador receberá seis cartas aleatórias. O restante das cartas fica empilhado em um montante de compra. Como mostra a Figura 1, o jogo começa com a retirada de uma carta do montante de compra e posicionando-a no centro do local onde será formada a cronologia, exibindo o verso. Com as cartas mostrando apenas a frente, pois não poderão ver o verso, o jogador insere uma das suas cartas no local que julgar correta. Após a inserção, é revelado o verso, contendo a data e a descrição da carta. Se o jogador posicionar a carta no local correto, então ele acertou a jogada e o jogo continua. Caso contrário, a carta é deslocada para a posição correta na linha do tempo e, como penalidade, o jogador retira uma nova carta do montante de compra e o jogo prossegue. O próximo jogador faz sua jogada da mesma maneira. No jogo, vence quem depositar primeiro todas as cartas das mãos na linha do tempo ou quem tiver com menos cartas em mãos quando o montante de compra acabar.

\footnotetext{
$1 \mathrm{http}: / /$ eniacprogrammers.org/

${ }^{2}$ http://gameinclass.ic.ufmt.br/computassy/index.html
} 


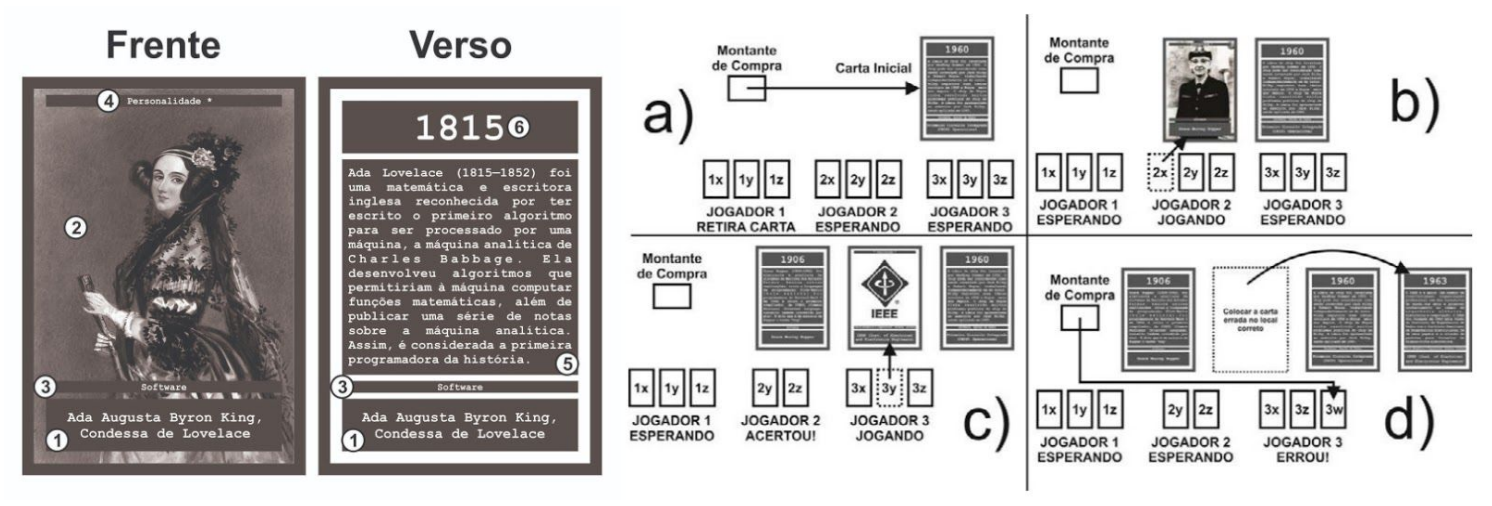

Figura 1: Exemplo de carta e seus elementos indicados e passos demonstrativos de uma jogada (Santos e Figueiredo, 2016).

\section{Metodologia}

A adoção do jogo Computasseia foi iniciativa de alunas do projeto Meninas Digitais do Vale que visa fortalecer a participação feminina em cursos de Ciência da Computação e Engenharia de Software da Universidade Federal do Ceará (UFC) no campus de Russas. Uma das ações deste projeto consiste em divulgar a área da Computação para estudantes do ensino fundamental e médio.

A experiência com o jogo Computasseia ocorreu primeiramente em duas turmas de cursos de extensão da UFC ofertados para estudantes do ensino médio do município de Russas. Os cursos são direcionados ao desenvolvimento de jogos e desenvolvimento de aplicativos acessíveis, respectivamente. Posteriormente, o jogo também foi adotado como estratégia para discutir sobre a participação de mulheres na área de Computação em um evento promovido pelo projeto, o Ada Lovelace Day. Durante o evento, participaram da experiência com o jogo, estudantes de graduação dos cursos de Engenharia de Software e Ciência da Computação.

Os grupos de participantes das diferentes experiências, serão denominados Turma 1, Turma 2 e Turma 3. A Turma 1 era composta por 13 estudantes de ensino médio de uma escola particular, a Turma 2 era composta por 20 estudantes de ensino médio de escolas públicas e a Turma 3 era composta por 12 estudantes de graduação.

Antes do uso do jogo, uma aula expositiva sobre História da Computação foi conduzida nas Turmas 1 e 2. Para a Turma 3 que é a turma de graduação não houve a necessidade de mostrar o conteúdo, porque os estudantes já tinham conhecimento sobre o conteúdo. Em seguida, o jogo Computasseia foi adotado para que os estudantes pudessem aplicar e avaliar o seu conhecimento sobre História da Computação. Ao final da experiência com o jogo, os vencedores de cada equipe eram premiados.

Com o intuito de investigar a experiência dos estudantes com o jogo, foi elaborado um questionário com afirmativas sobre o design, a relevância, a confiança, a satisfação, o desafio, a habilidade e a interação social. $\mathrm{O}$ questionário é baseado no modelo MEEGA+ para avaliação de jogos educacionais em Computação. Contudo, o questionário elaborado é uma versão mais simplificada do questionário proposto pelo modelo MEEGA+ (Petri, et al. 2017).

Os estudantes deveriam indicar o seu grau de concordância com as afirmativas do questionário por meio de uma escala de Likert de 5 pontos variando de "concordo 
totalmente" a "discordo totalmente" com uma opção neutra "nem concordo, nem discordo".

\section{Resultados}

Nesta seção, serão apresentados os gráficos comparativos entre as três turmas, possibilitando a observação da percepção dos estudantes, em relação à execução do jogo e ao design e conteúdo jogo. Não foi possível realizar a comparação das percepções dos estudantes por gênero, porque na primeira versão do questionário não haviam questões de caracterização do perfil do estudante, somente na segunda versão essas questões foram adicionadas. A Figura 2 mostra cada gráfico com as respostas obtidas de cada turma para cada afirmativa do questionário.

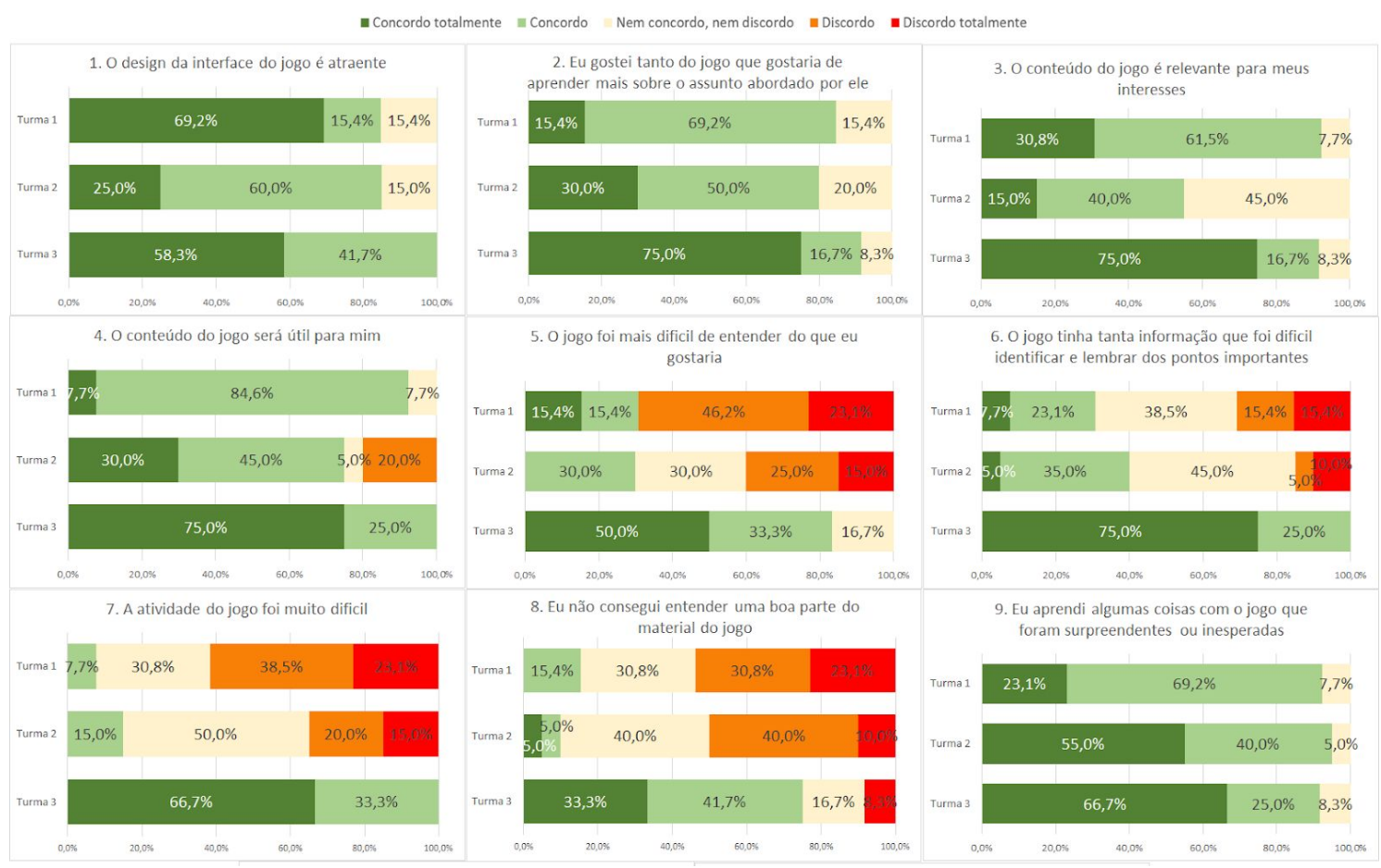

Figura 2: Resultado do questionário respondido pelos alunos das duas turmas do ensino médio e da graduação.

As respostas das turmas 1 e 2 (turmas do ensino médio) representadas no gráfico 2 são bastantes semelhantes, entretanto a turma 3 (turma da graduação) demonstra maior interesse em aprender mais sobre o assunto (afirmativa 2). Mais da metade dos alunos da turma 2 foram indiferentes quanto à relevância do assunto do jogo (afirmativa 3). Em relação à afirmativa 4, alguns alunos da turma 2 afirmaram que o conteúdo não é útil para eles.

Sobre a dificuldade em entender o jogo (afirmativas 5 a 8), as turmas de ensino médio discordaram que o jogo foi difícil de entender e de identificar pontos importantes do jogo, como é apresentado nos gráficos 5, 6, 7 e 8. Já os alunos de graduação apresentaram dificuldades em entender o jogo. Devemos ressaltar que as turmas 1 e 2 que são as turmas do ensino médio tiveram aula sobre a História da Computação, antes da aplicação do jogo, levando a um conhecimento prévio sobre o assunto e a turma 3 que é a turma de graduação já tinha um conhecimento sobre o conteúdo. Entretanto, a quantidade de informações contidas na frente e verso das cartas, pode ter dificultado no momento de lembrar no decorrer do jogo. 
Por meio da questão aberta, solicitando 3 pontos forte do jogo, foram obtidas respostas, como: "o jogo é divertido", "fácil de jogar", "possibilitou o aprendizado sobre a história da computação", "possui uma interface atraente" e "proporcionou uma interação entre o grupo", "apresenta personalidades importantes e marcantes", os alunos também informaram que "o jogo é uma nova forma de aprender sobre a computação e seus protagonistas". Esses resultados reforçam que os jogos aliados a conteúdos escolares podem estimular a criação de estratégias, exigindo habilidades que constituirão importantes competências na relação ensino-aprendizagem.

\section{Considerações Finais e Trabalhos futuros}

Este artigo descreve a aplicação e avaliação de um jogo de cartas que mostra os principais fatos e personalidades importantes da História da Computação. A experiência de aplicar o jogo como método de ensino tornou a experiência de ensino-aprendizagem mais atrativa, dinâmica, com maior participação dos estudantes. Esta experiência fornece evidências de que a utilização do Computasseia no ensino de História da Computação permite ao estudante experimentar um processo de aprendizagem como maior motivação, interesse e engajamento e contribui para o reconhecimento das mulheres e para o incentivo da participação feminina na área da TI.

Como trabalhos futuros, pretende-se: elaborar um questionário com foco na percepção sobre o conteúdo do jogo, investigar a percepção dos resultados por gênero e realizar a atividade com estudantes ingressantes da graduação dos cursos de Engenharia de Software e Ciência da Computação.

\section{Referências}

Oliveira, A.C., Moro, M.M., Prates, R.O. (2014). "Perfil Feminino em Computação: Análise Inicial” In: XXII Workshop sobre Educação em Computação, Brasília, DF, p. 14651474.

Oreskes, N. (1996). "Objectivity or heroism? On the invisibility of women in science", In: Osiris, 11, p. 87-113.

Pessoa, M. S. P., Tamayo, S. G., Rodrigues, J. (2017). "Aumento da participação feminina em competições de programação tecnológicas através da criação de grupos de treinamento e pesquisa". In: $11^{\circ}$ Women in Information Technology (WIT 2017). Vol. 11. No. 1/2017. SBC, 2017.

Petri, G., von Wangenheim, C. G., \& Borgatto, A. F. (2017). Evolução de um Modelo de Avaliação de Jogos para o Ensino de Computação. In $25^{\circ}$ Workshop sobre Educação em Computação (WEI 2017) (Vol. 25, No. 1/2017).

Figueiredo, K.S., Santos, J. C. O. (2016). "Computasseia: destacando a participação feminina na História da Computação". In: WOMEN IN INFORMATION TECHNOLOGY (WIT_CSBC), 2016.

Santos, J. C. O., Figueiredo, K. S. (2016). Computasseia: Um Jogo para o Ensino de História da Computação. In $24^{\circ}$ WEI-Workshop sobre Educação em Computação, XXXVI Congresso da Sociedade Brasileira de Computação, Porto Alegre. 